\section{CASE OF TETANUS}

CONSEQUENT UPON

\section{BURNS FROM CAUSTIC POTASH.}

RECOVERY UNDER THE USE OF ASSAFGTIDA.

By T. M. Markoe, M.D.,

House Surgeon to the New York Hospital.

John Brady, aged 32, an Irish labourer, was admitted May 22, 1841, with tetanus supervening during the cicatrisation of several burns on his feet. These burns were caused by caustic potash, upon which he accidentally stepped about five weeks before his admission. The injury was principally confined to the soles of his feet, but extended up between several of his toes. The caustic acted to a considerable depth, and the sores left by the eschars had scarcely filled up when the tetanic symptoms set in. The ulcers were then rather callous, improving very slowly and without much pain. He was admitted on the fourth day of the disease: The affection had come on in a gradual manner, with at first slight pain and stiffness about the jaws, and occasionally a difficulty in swallowing. When admitted, the disease had not extended beyond the muscles of the jaws, which were firmly clenched, and could not be opened a fourth of an inch. He complained of severe pains shooting down the back of his neck and over the insertion of the temporal muscle. Any effort of swallowing, or even speaking, brought on spasm of the affected muscles, attended with great increase of pain. He complained also of pain in the abdominal muscles shooting towards the spine. His pulse is not much above the natural standard as to strength or frequency. Skin bathed in a profuse perspiration. His bowels have been disposed to be costive, though freely opened yesterday by a dose of salts. His nights have been very restless, and he has scarcely slept since the disease commenced. The feet were poulticed, and in order to give him a good night's rest he was ordered to take ten drops of solut. sulph. morph. every two hours, until sleep was produced. He took in all fifty drops, after which he passed a comfortable night, sleeping seven or eight hours.

23. Feels much more free from pain, though there is no improvement in the tetanic symptoms. He was put upon the use of assafœtida, five grains every two hours, and every intermediate hour half an ounce of tinct. rhei, in order to keep his bowels free.

24. Passed a very restless night; says he feels more pain than ever about his jaws; the abdominal muscles are very tense, and he complains of great pain at the scrobiculis cordis; the spasms are more frequent and more severe; perspiration constant and very profuse; no change in the pulse. The tinct. rhei has been taken regularly every two hours, without any effect upon the bowels; he was given a common enema, which brought away an immense discharge of fæces, after which he felt much more comfortable, though without visible relaxation of the jaws.

25. No marked change. He has occasionally a disposition to opisthotonos, though not severe; profuse sweat still continues.

26. The spasms have become more frequent and severe, and attended with excessive pain. Though he has continued the tinct. rhei regularly, the bowels have not been again opened. He was ordered to take one comp. aloetic pill every other hour, instead of the rhubarb, and to continue the assafœtida.

27 . He seems very desponding about himself, having passed another sleepless night. The spasms are more severe and frequent, affecting the muscles of the back. Sweat very profuse, and pulse rather more feeble, though not accelerated. Allowed a little brandy milkpunch with his nourishment, and an enema given. The enema, as before, brought away a large fœeal discharge, and immediately after its operation he felt much relieved. The jaws became so much relaxed, that he could protrude half an inch of his tongue.

28. Spasms have come on again more severe than ever; he has bitten his tongue during sleep so severely that he can scarcely swallow a drink of the thinnest gruel. As he could no longer swallow, he was given every two hours a small enema containing half an ounce of tincture of assafœtida.

30. No marked improvement while awake, but it was noticed that during sleep the mouth could be opened nearly to its full extent without pain. Bowels. opened every other day with an enema.

June 3 . Since the last date there has been a decided improvement in his condition. The spasms are less frequent and less severe, and he complains less of pain about the umbilicus. He is able to sleep sometimes half an hour without being awakened by a convulsion. He is able now to resume the assafœtida pills ; injection of assafœtida was, therefore, discontinued.

10. Is rapidly improving; can open his mouth at times nearly as wide as ever. The spasms have almost ceased, and are very trifling when they do occur. His appetite is good, and he begins to chew soft food without difficulty. He is able to walk a few steps without assistance. In crossing the hall, however, this morning, he stumbled upon something, and a paroxysm coming on at the time, he fell at full length perfectly stiff, striking his face against the floor, and slightly wounding his lip. This is the worst paroxysm he has had for a week, and was probably aggravated by his sudden efforts to save himself from falling.

15. No increase of disease has followed the fall, and he has continued regularly to improve. He now takes the assafœtida pills only in the daytime, occasionally one or two pill. aloetic comp. He eats hearty, sleeps well, and walks about without difficulty. He has now no spasms more than occasional slight cramps. The burns are nearly healed. From this time he continued to improve, and was discharged, cured, June 30,1841 .

I may remark, in conclusion, that this is the third successive case of traumatic tetanus which, under Dr. Watson's care, has recovered under the use of assafotida. For the details of all the other cases in which his practice has been employed, see N. Y. Journ. of Med. and Surg. for Oct., 1840.-American Journ. of Med. Sciences, No. 4.

\section{FISSURE OF THE ANUS CURED BY RATANHY.}

Several cases, illustrating the good effects of enemata containing ratanhy in fissure of the anus, have been published in the "Journal des Connaissances Medico-Chirurgicales." Four additional cases are related in the last number of the same journal. The characteristic sign of fissure of the anus is a fixed pain in some point round the margin of the anus ; the pain is always increased during the evacuation of the bowels, and is mitigated during the intervals between each stool. In most cases the sphincter ani is so firmly contracted, that the introduction of the finger, of a canula, or even a strip of lint, gives excessive pain. When the patient goes to stool he feels a sensation of heat and scalding, followed by pulsation and lancinating pains in the fundament; these occur so constantly that the patients feel a great repugnance to go to stool, are deprived of sleep, and so suffer in their general health. The fissure, when examined, commonly appears like one of those cracks which we see on the lips, or on the nipples of nurses, and generally occupies the radiating folds of the anus. The following case, selected from the four cases alluded to, illustrates the efficacy of the treatment employed by M. Trousseau :-

On the 17 th of June, 1841, a woman was admitted into the Necker Hospital, six weeks after her ac- 
conchement. She says that she never had piles; but an examination of the anus leads to the idea that she must have suffered from them. Whenever she goes to stool she experiences a very acute pain in the anus, followed by painful pulsations, which last eight or ten hours. On pressing with the finger over the anterior and lateral parts of the anus, no pain is occasioned; but behind, towards the coccyx, the finger occasions excessive pain, and distinguishes a fissure about seven lines in length.

A simple enema was thrown up to empty the bowels; and afterwards another enema, containing four scruples of extract of ratanhy, one of alcohol, and eight ounces of water. On the 19th the pain after each stool had diminished; the ratanhy lavement excited a little pain, but of a different kind from that produced by the fissure.

24. Pain almost entirely gone; one enema per day, instead of two, was now administercd.

On the 8th of July all pain had ceased. A lavement every second day. On the l6th the patient was discharged completely cured. She promised to return to the hospital if she had any relapse, but was never seen since.

M. Bretonneau was the first who suggested the idea of treating this disease with encmata of ratanhy; since then he has modified his mode of administering the remedy, and in some cases, especially where the fissure is very deep, he keeps up a constant current in the rectum. The good effects of this latter method are illustrated by a case which occurred in the practice of $\mathbf{M}$. Bretonneau. A lady had been treated by the ratanhy lavements in the usual way, and for a considerable time, without any benefit. Her medical attendant now wrote to $M$. Bretonneau, who recommended the constant current to be kept up; after the fourth day all pain had ceased, and the lady was cured in eight days.

\section{PROVINCIAL}

\section{MEDICAL \& SURGICAL JOURNAL}

\section{SATURDAY, MARCH 19, 1842.}

It is now some time since that restless desire for change which occasionally arises, and has of late been felt in all the institutions of this country, has shown itself also among the members of the medical profession. The state, the commonwealth of trade, the republic of science, severally in their turns suffer from the workings of this spirit, which, however it may ultimately conduce to beneficial ends, generates much contention, and much immediate evil, before the good anticipated and sought for can possibly be obtained. Civilisation and the recognition and definition of social and individual rights are progressive. The laws and regulations, therefore, which are fitting for one period, leaving out of the question the abuses which negligence and interested motives are ever generating, are in themselves not equally well adapted to that which succeeds. The relations in which we stand to each other, and to the general community, are constantly varying; new wants arise, while some of those which at one time were felt, and required to be provided for, are now no longer of the same pressing importance. Changes, therefore, calculated to meet these rariations of circumstances, are from time to time demanded; and when these can no longer be with advantage dispensed with, the necessity for what is called reform exists.

Noterm has been more abused, to whatever object it has been applied, than the term reform. It has been tormented and twisted under the hands of those that employ it, and those that eschew it, until the very idea which it originally conveyed has been lost sight of. Reform, in its correct sense, is the remodelling of institutions, the value of which has been admitted and felt, the removal from these of what is obsolete and injurious to their efficiency, and the adding to them what is required to fit them, under altered circumstances, for the purposes for which they were originally designed, and for others to which they may be made slibservient with advantage. No prudent man dreams of razing to the foundation the house which he has inherited from his ancestors, simply because the roof may admit the rain, or his library may have become more extensive than the apartment allotted to it will conveniently contain. He contents himself with having the roof properly repaired, or with making such alterations or addition to the original building as is requisite for the occasion. If he be a man of sound judgment and correct taste, he will also take care that the changes introduced shall accord with the character of the general structure. He will not superimpose a Gothic roof upon a Grecian building, nor will he append a wing to contain his library built in the Tuscan or Doric style of architecture, when the general construction of the house belongs to the Elizabethan period.

Extensive change is always to be deprecated. It is an evil under any circumstances, and can only. be tolerated because to remain as we are is a greater evil. When it becomes necessary, therefore-when reform is really called for, though, from the varying circumstances attendant upon progressive civilisation, and a lighly artificial state of society, we cannot hope to attain to finality-it should be an object to come so near to what our wants demand as to render it unnecessary soon to have recourse to fresh changes, to renewed agitation, before the merits of those which have been made can become fully appreciated. In remodelling, therefore, our medical institutions, we would by no means level them with the dust. They contain, as we believe, much that is valuable, and, as being of long-tried utility, to be touched with a cautious hand. Our object is rather to remove from them the parasitical excrescences with which time has invested them, to restore them in part to their original integrity, to render them better fitted to fulfil the purposes for which they were originally formed, and so to modify them, by the introduction of new regulations, as to extend their usefulness, and to prevent the recurrence of those abuses which now disfigure them, and impair their efficiency.

If we had to give for the first time a form and sub. stance to the medical polity, to call the whole superstructure into being, it would be well, perhaps, to take a wider view, and to embrace within the limits 